\title{
Analysis of the efficacy of an internet-based self-administered intervention ("Living Better") to promote healthy habits in a population with obesity and hypertension: An exploratory randomized controlled trial
}

\author{
Marinna S. Mensorio ${ }^{\mathrm{a}, \mathrm{b}}$, Ausiàs Cebolla-Martí ${ }^{\mathrm{a}, \mathrm{c}}$, Enrique Rodilla ${ }^{\mathrm{d}}$, Gonzalo Palomar ${ }^{\mathrm{e}}$, \\ Juan Francisco Lisón ${ }^{\mathrm{f}}$, Cristina Botella ${ }^{\mathrm{g}, \mathrm{c}}$, Fernando Fernández-Aranda ${ }^{\mathrm{h}, \mathrm{c}}$, \\ Susana Jimenez-Murcia ${ }^{\text {h,c }}$, Rosa M. Baños ${ }^{\mathrm{a}, \mathrm{c}, *}$

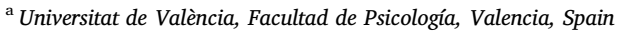 \\ b CAPES Foundation, Brazil \\ ${ }^{\mathrm{c}}$ CIBER Fisiopatología Obesidad y Nutrición (CB06/03), Instituto Carlos III, Spain \\ ${ }^{\mathrm{d}}$ Hypertension and Vascular Risk Unit, Hospital de Sagunto, Sagunto, Spain \\ ${ }^{\mathrm{e}}$ Primary Care Health Center, Quartell, Spain \\ ${ }^{\mathrm{f}}$ Universidad CEU Cardenal Herrera, Departamento de Medicina, Valencia, Spain \\ ${ }^{\mathrm{g}}$ Universitat Jaume I. Castellón, València, Spain \\ ${ }^{\mathrm{h}}$ University Hospital of Bellvitge-IDIBELL, Department of Psychiatry, Barcelona, Spain
}

A R T I C L E I N F O

\section{Keywords:}

Online intervention

Obesity

Overweight

Hypertension

Lifestyle change

\begin{abstract}
A B S T R A C T
Introduction: Changes in unhealthy lifestyles are key elements in the prevention and treatment of obesity and hypertension. Internet-based programs offer great potential for the implementation of evidence-based interventions focused on promoting healthy habits. We evaluate the efficacy of an Internet-based self-administered program ("Living Better") that addresses people diagnosed as being overweight or having type I obesity and hypertension.

Methods: The sample was composed of a total of 106 participants (age Mean = 53; 59 males) from a public hospital in Spain, diagnosed as being overweight or having type I obesity and hypertension and randomized into two groups - the intervention group (IG; Internet-based intervention) and the control group (CG; usual medical treatment). The intervention used cognitive-behavioral strategies and psychoeducation to promote healthy habits. Anthropometric data (i.e., Body Mass Index -BMI-, waist circumference, and hip circumference) and lifestyle/psychological data (i.e., quality of life, physical activity, eating styles, motivation, mood, and self-efficacy) were assessed before and after the intervention, and at 6 and 12-month follow-ups.

Results: Significant differences were observed between the IG and the CG in anthropometrical variables after intervention (i.e., BMI and waist circumference), external eating style, and anxiety and stress scores (p < 0.05). Follow-up data showed that changes were maintained in BMI, waist and hip circumference, and external eating in the IG. After receiving the Internet-based treatment, the CG also improved its clinical condition.

Discussion: This study demonstrates that the Internet is a viable alternative for the delivery and dissemination of interventions focused on promoting healthy habits, and a totally self-administered intervention can produce long-term positive results.
\end{abstract}

\section{Introduction}

Lifestyles are one of the most important determinants of health.
Sedentary behaviors, consumption of fatty foods, fast food, tobacco, alcoholic beverages, stress, among other factors, are currently the most important causes of mortality and illness [1-3].

\footnotetext{
Abbreviations: BMI, Body Mass Index; IG, Intervention Group; CG, Control Group

* Corresponding author at: Universitat de València, Facultad de Psicología, Av. Blasco Ibanez, 21. Departament de Personalitat, Avaluació i Tractaments Psicològics. Universitat de València. 46010, València, Spain.

E-mail addresses: ninamensorio@gmail.com (M.S. Mensorio), acebolla@uji.es (A. Cebolla-Martí), rodilla_enr@gva.es (E. Rodilla),

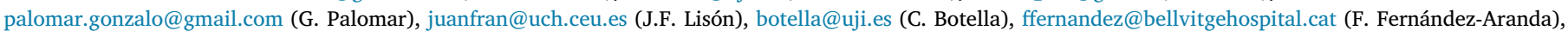
sjimenez@bellvitgehospital.cat (S. Jimenez-Murcia), banos@uv.es (R.M. Baños).
} 
Lifestyles have also a decisive influence on the maintenance of chronic diseases, including obesity and arterial hypertension [4,5]. The prevalence of these two conditions has been rising over the past decades, as has the economic burden, and both have a significant economic impact on the health care system [6,7]. Several treatment modalities have been designed and implemented for obesity and hypertension (e.g., pharmacological, nutritional, surgical, and psychological), but the unanimous conclusion is that there is no long-term solution without a profound change in the way patients relate to food and physical activity [1]. Unfortunately, the data indicate that these usual medical procedures to promote these healthy habits are not effective enough [8]. This may in part be attributable to the substantial barriers that undermine long-term strategies. These can include lack of adherence with treatment, lack of motivation, time constraints, lack of recognition of obesity or hypertension as chronic conditions, or lack of consistent follow-ups $[9,10]$.

The use of Information and Communication Technologies (ICTs), especially Internet-based interventions are demonstrating great potential in the delivery of prevention and treatment programs focused on promoting lifestyle changes and in particular as support for weight loss. These interventions are becoming highly valuable allies for clinicians and patients by promoting the continuous accompaniment of patients without the need for face-to-face meeting, travel, or extra expenses [11].

The efficacy of ICTs for delivering treatments has already been proven in several chronic diseases $[12,13]$. There are currently several reviews evaluating the effectiveness of Internet-based interventions to promote weight loss or improve lifestyle. The meta-analyses performed by Neve et al. [14], Manzoni et al. [15], Kodama et al. [16], and Dutton, Laitner, and Perri [17] show that the use of the Internet in treatment programs has a modest but significant effect on weight control. However, these reviews also point out variations among trials (with smaller effect sizes and inconsistent results across studies), and the need for better descriptions of components of effective interventions [15], although they emphasize the promising nature of Internet-based interventions.

Regarding hypertensive and at cardiovascular risk populations, although the studies analyzing and comparing online interventions with the usual treatments are still scarce, the use of Internet-based interventions has shown to be effective at reducing cardiovascular risk factors $[18,19]$. Generally, these interventions use components similar to those for obese populations.

Most of the randomized clinical trials (RCTs) that analyze online interventions for these conditions have focused mainly on weight change and some medical variables, and few studies assess the effect of treatments on changing lifestyles and relevant psychological variables [20]. For instance, some studies have highlighted the effects of Internetbased interventions on food behavior change (including better food choices after online intervention) [21-24], improvements in self-efficacy $[22,25,26]$ and stress reduction [25]. Therefore, more research is needed into the effects of online interventions on psychological variables. In addition, to our knowledge there are no studies that evaluate anthropometric and psychological variables jointly on a sample of obese patients with hypertension.

The objective of this study is to assess the efficacy of a completely self-administered Internet-based intervention aimed at promoting lifestyle changes in obese and hypertensive patients by comparing the results with a waiting list group (control group).

\section{Methods}

\subsection{Study design}

This study was an exploratory RCT with two arms: the intervention group (IG) and the control group (CG). The study was conducted following the CONSORT statement (Consolidated Standards of Reporting
Trials) and CONSORT-EHEALTH guidelines [27,28]. Trial Registration number: NCT02445833 [21]. This study has been approved by the Ethics Committee for Clinical Research at the Hospital de Sagunto (ref: 002-2014-10) and by the Ministry of Health, Social Services and Equality in the Spanish Government (s/n), as a post-authorisation observational study.

\subsection{Sample}

The sample consisted of patients regarded as being overweight or having type I obesity, hypertension, and under medical supervision in the Hypertension and Vascular Risk Unit of a public hospital (Spain). Participants were recruited by the physicians, and met the following criteria: age 18-65 years, in clinical medical treatment for the prevention of metabolic syndrome or cardiac complications, and overweight or type I obesity (Body Mass Index - BMI $>25$ and $<35$ ). Exclusion criteria were no Internet access, taking more than three antihypertensive drugs, a diagnosis of diabetes, a diagnosis of eating disorder, having a disability that prevents or hinders exercise and physical activity, or receiving any treatment for weight loss elsewhere. The sample size was calculated based on the effect size for body weight finding in previous studies [15,30,31].

From the initial selection of patients made by the physicians $(\mathrm{n}=510), 106$ patients finally accepted (55 in the IG and 51 in the CG). Fig. 1 shows the flow of participants throughout the study. All participants in the post-test and follow-ups completed all online modules. If they failed to complete the modules at some point in the program, they were considered dropouts. Most of the participants who left the study at some point did not offer further explanations. Among those who did explain the reason for abandoning or not completing the study, the following stand out: lack of interest, health problems, difficulty in managing computer/Internet, and family problems.

\subsection{Procedure/recruitment}

After selection of patients who fit the inclusion criteria, a letter was sent to inform them of the study. Once patients agreed to participate, they were asked for their informed consent at the hospital, and allocated to one of two groups: IG and CG. Randomizations were performed using random allocation software (with the program Epidat 4.1) [29].

- Online treatment (IG): They received an intervention program (in addition to usual medical treatment) with support of the website created and designed for the objectives of this study (the program description was made in Baños et al. [29].

- Control group (CG): They received the usual medical consultations focused on reducing cardiovascular risk factors. The usual treatment consists of routine medical examinations in which patients are monitored and provided with information on lifestyles and diet (usually one medical visit every $6-8$ months on average). At 3 months, these participants were offered the possibility of performing the intervention online. The online intervention was offered to comply with the instructions of the Ethics Committee, and to allow all participants to benefit from the treatment.

There were four evaluation moments for the IG group: before the intervention (M1: PRE), after the intervention (M2: POST), and two follow-ups (M3: 6 months, psychological variables and M4: 12 months, medical and psychological variables).

The CG had two pre-treatment evaluation moments (M1: PRE1 and M2: PRE2), which correspond to the PRE and POST of the IG. Patients from this group who accepted, received the online intervention, and were evaluated after finishing it (M3: POST, for psychological variables) and after 1 year (M4: for anthropometrical variables). These differences between M3 and M4 were due to problems in the availability of the participants. 


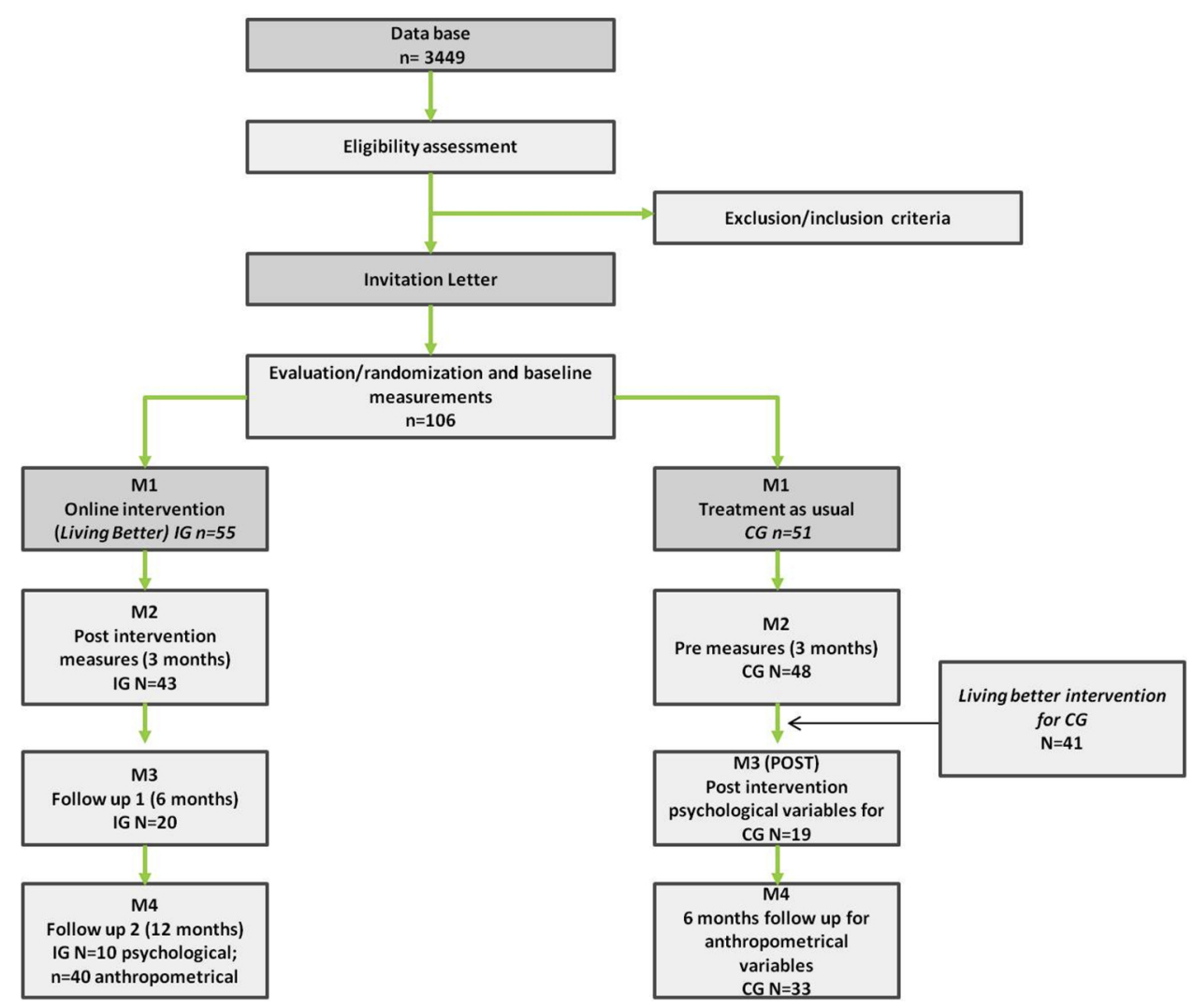

Fig. 1. Study participants flow.

M1: pre-intervention; M2: post intervention for IG and Pre-intervention 2 for CG; M3: 6 months follow-up for IG and post-intervention for CG; M4: 12 months followup for IG and 6 months follow-up for CG.

\subsubsection{Internet-based intervention "Living Better"}

The self-administered online intervention ("Living Better") is composed of nine modules and presented via a web page aimed at progressively establishing healthy eating habits and increasing the level of physical activity as recommended by the guides [32,33].

The program followed a cognitive-behavioral approach and is based on three fundamental pillars: behavioral therapy techniques, promotion of eating habits, and physical activity. The sessions contained psychoeducation about what a healthy lifestyle involves and learning techniques on how to achieve it on a day-to-day basis. Some of the techniques used are self-observation, self-instructions, behavioral recording, stimulus control, self-reinforcement, problem-solving techniques, and homework. In addition, the web page offered useful tools, such as downloading documents online and videos. Participants accessed the program through a computer (no mobile version was developed). The program has been described in more detail in Baños et al. [29].

\subsubsection{Outcome measures}

2.3.2.1. Overview. Anthropometric measures were carried out face-toface at the hospital at baseline, 3 months, and 12 months (equivalent dates for both groups). Psychological assessments were carried out online via the Survey Monkey platform. The surveys were e-mailed out to be answered by the patients at baseline, 3 months, 6 months, and 12 months (equivalent dates for both groups).

The following variables were assessed:

Body Mass Index (BMI = kilogram $/$ meter $\left.^{2}\left[\mathrm{~kg} / \mathrm{m}^{2}\right]\right)$.

Waist and hip perimeter (centimeters).

International Physical Activity Questionnaire (IPAQ-short) [34]: Selfreport containing 7 items that collect information about physical activity and sedentary behavior.

Quality of life (QLI) [35]; Spanish version [36]: This includes 10 items, with a multiple choice Likert response format on a scale from 1 to 10 , assessing different areas related to quality of life.

Self-Efficacy Questionnaire General (GSES-12) [37]: It is a self-report scale consisting of 10 items with a 4-point Likert scale, designed to assess overall sense of efficacy.

Dutch Eating Behaviours Questionnaire (DEBQ) [38]; Spanish validation [39]: It is composed of 33 items, with a 5-point Likert scale, that evaluates 3 styles of eating: emotional eating (13 items), external eating (10 items), and restrictive eating (10 items).

Depression, Anxiety, Stress Scale (DASS-21) [40]; Spanish validation [41]: This abbreviated 21-item version (4-point Likert scale) is a selfreport that measures the symptoms related to anxiety, depression, and stress during the previous week. The total scores are classified into five levels of symptomatology: normal, mild, moderate, severe, and very severe.

Behavioral Regulation in Exercise Questionnaire-2 (BREQ-2) [42]; Spanish validation [43]: It consists of 19 items, which measure stages of the self-determination continuum (external regulation, introjected, identified, and intrinsic motivation) on a 5-point Likert scale. An adaptation of this scale was made to assess motivation to change eating habits (not validated so far).

\subsection{Statistical data analysis}

SPSS v.20 was used for statistical analysis. Relevant statistical analyses were first performed to verify proper randomization (independent samples $t$ test). A series of repeated-measures mixed analyses of variance ANOVAs with planned contrasts $(2 \times 2)$ were carried out (first phase of analysis) with intergroup variable (condition: IG vs. CG) $\mathrm{x}$ intragroup variable (time: pre- vs. post-) for each dependent variable. Bonferroni post-hoc tests were applied, and the intention-to-treat (ITT) analysis procedure was used. 
XXX.

\begin{tabular}{|c|c|c|c|c|c|c|c|c|}
\hline \multirow[b]{2}{*}{ Anthropometric variables } & \multicolumn{2}{|c|}{ Total $(\mathrm{n}=106)$} & \multicolumn{2}{|c|}{ CG $(n=51)$} & \multicolumn{2}{|c|}{ IG $(n=55)$} & \multirow[t]{2}{*}{$p$} & \multirow[t]{2}{*}{$t$ value } \\
\hline & M & SD & M & SD & M & SD & & \\
\hline BMI & 30.11 & 2.79 & 30.15 & 2.96 & 30.08 & 2.65 & .02 & .136 \\
\hline Weight & 82.71 & 14.53 & 81.5 & 12.02 & 83.83 & 16.56 & -.12 & -.826 \\
\hline Waist circumference $(\mathrm{cm})$ & 99.09 & 8.72 & 98.14 & 7.94 & 99.98 & 9.39 & -.20 & -1.08 \\
\hline Hip perimeter $(\mathrm{cm})$ & 106.2 & 6.04 & 106.29 & 6.88 & 106.24 & 5.20 & 1.32 & .045 \\
\hline \multicolumn{9}{|c|}{ Psychological and lifestyle variables } \\
\hline \multicolumn{9}{|c|}{ Physical activity (IPAQ) } \\
\hline Mets & 5591.2 & 7325.7 & 4903.6 & 5137.6 & 6116.9 & 8643. & -.17 & -.807 \\
\hline Quality of life & 7.08 & 1.25 & 7.17 & 1.12 & 7.01 & 1.34 & .08 & .630 \\
\hline Self-efficacy (GSES) & 32.30 & 4.99 & 33.19 & 4.26 & 31.61 & 5.43 & .31 & 1.54 \\
\hline \multicolumn{9}{|c|}{ Motivation towards food (BREQ-AF) } \\
\hline Intrinsic & 13.18 & 3.17 & 13.16 & 2.89 & 13.19 & 3.41 & .00 & -.05 \\
\hline Identified & 13.09 & 1.88 & 13.06 & 2.04 & 13.11 & 1.77 & .02 & -.122 \\
\hline Introjected & 9.56 & 2.86 & 9.27 & 3.17 & 9.80 & 2.58 & .18 & -.883 \\
\hline External & 8.56 & 3.59 & 8.44 & 3.71 & 8.66 & 3.51 & .06 & -.301 \\
\hline Demotivation & 7.09 & 3.03 & 6.81 & 2.85 & 7.33 & 3.19 & -.17 & -.824 \\
\hline \multicolumn{9}{|c|}{ Motivation towards PA (BREQ) } \\
\hline Intrinsic & 15.18 & 3.70 & 15.46 & 3.48 & 14.94 & 3.89 & .14 & .682 \\
\hline Identified & 15.52 & 2.80 & 15.44 & 2.69 & 15.58 & 2.92 & -.04 & -.250 \\
\hline Introjected & 8.96 & 3.34 & 8.46 & 3.39 & 9.39 & 3.28 & -.27 & -1.34 \\
\hline External & 7.20 & 3.84 & 6.88 & 3.64 & 7.47 & 4.02 & -.15 & -.735 \\
\hline Demotivation & 5.87 & 2.59 & 6.16 & 3.03 & 5.62 & 2.17 & .20 & .967 \\
\hline \multicolumn{9}{|l|}{ Eating style (DEBQ) } \\
\hline Emotional & 28.07 & 10.84 & 29.06 & 11.16 & 27.27 & 10.63 & .16 & .807 \\
\hline Restrictive & 28.75 & 5.96 & 28.44 & 6.53 & 29.00 & 5.52 & -.09 & -.456 \\
\hline External & 28.84 & 7.01 & 29.23 & 7.66 & 28.53 & 6.50 & .09 & .483 \\
\hline \multicolumn{9}{|l|}{ Mood state (DASS) } \\
\hline Anxiety & 3.13 & 3.98 & 2.53 & 3.18 & 3.63 & 4.51 & -.28 & -1.43 \\
\hline Depression & 2.49 & 3.22 & 1.97 & 2.72 & 2.92 & 3.55 & -.30 & -1.38 \\
\hline Stress & 4.94 & 3.79 & 4.34 & 3.63 & 5.44 & 3.88 & -.29 & -1.40 \\
\hline
\end{tabular}

Mean and standard deviation of anthropometric and psychological measures.

In the follow-up (second and third phase of analysis), unifactorial ANOVAs $(1 \times 3)$ of repeated measures with three moments were applied to evaluate the effect of the treatment in the follow-ups and in the two groups.

\section{Results}

\subsection{Baseline characteristics}

The mean age of the initial sample was 53 years $(\mathrm{SD}=8.9$, range $=28-69$ ); the mean $\mathrm{BMI}$ was $30.11 \mathrm{~kg} / \mathrm{m}^{2}$ (SD $=2.79$ range $=$ $25.1-40.6 \mathrm{~kg} / \mathrm{m}^{2}$ ); the mean systolic blood pressure was $130.2 \mathrm{mmHg}$ ( $\mathrm{SD}=13.9$, range $103-177 \mathrm{mmHg}$ ); and the mean diastolic pressure was $77.1 \mathrm{mmHg}(\mathrm{SD}=8.69$, range $=56-104 \mathrm{mmHg}$ ). The majority (55.5\%) were non-smokers and occasionally consumed alcohol (41.8\%) (24.5\% did not consume alcohol). Regarding physical activity, the majority of participants were active before the intervention, with moderate $(30 \%)$ or high $(48.2 \%)$ physical activity practice, and only $10 \%$ of the sample could be considered sedentary. There were no significant differences in any of the baseline characteristics between the two groups (Table 1 ).

\subsection{Efficacy of the online intervention: differences between the IG and the} CG at 3 months

The first phase of analysis compared the change between the two groups in the first 3 months (post-treatment) in all variables (Table 2 and Fig. 2). The ITT analysis showed that the IG significantly reduced BMI and waist circumference when compared to the CG.

Regarding the psychological variables, the IG significantly improved scores of intrinsic motivation towards physical activity, external eating, anxiety, and stress after receiving the intervention compared to the CG (confirmed by post-hoc analyses of Bonferroni) (Table 2 and Fig. 2).
The IG could also be observed having a tendency toward improvement of self-efficacy scores $(\mathrm{p}<0.06)$.

\subsection{Follow-ups for the IG (second phase of analysis)}

At 6 months follow-up, differences were found for IG participants (Table 3 and Fig. 3). Scores on external eating style remained low, decreasing significantly compared to the baseline moment. Scores on anxiety increased in the follow-up period. External motivation towards eating habits change decreased compared to baseline. At 12 months follow-up, no significant differences were found for any psychological variable, compared to the 6 month follow-up outcomes (Table 4).

Regarding anthropometric variables at 12 months follow-up, significant changes were found for the waist and hip circumference compared to baseline. No differences were observed in BMI (Fig. 4 and Table 5).

\subsection{Follow-up differences for the CG (third phase of analysis)}

In the third phase of analysis, the CG received the intervention, so that the effect of the intervention in this group was evaluated. The psychological variables were assessed in the immediate post-intervention and the anthropometric variables at 12 months.

In the post-intervention, the following differences were found for CG participants. First, increases in intrinsic and identified motivation and decreases in external motivation and demotivation towards the eating habits change compared to the baseline (Table 6 and Fig. 5). Second, scores on emotional eating and external eating decreased significantly after the intervention. Also, scores on anxiety and stress decreased. Finally, significant increases in IPAQ-short values and in QLI scores were also observed compared to the moment before receiving the intervention (M2) (Table 6 and Fig. 5,6 ).

Regarding the anthropometric variables at 12 months follow-up in 
Table 2

XXX.

\begin{tabular}{|c|c|c|c|c|c|c|c|c|c|c|c|}
\hline \multirow[t]{3}{*}{ Variables } & \multicolumn{4}{|l|}{ Groups } & \multicolumn{7}{|l|}{ Effects } \\
\hline & \multicolumn{2}{|l|}{ CG } & \multicolumn{2}{|l|}{ IG } & \multicolumn{2}{|c|}{ Moment } & \multicolumn{2}{|c|}{ Groups } & \multicolumn{3}{|c|}{ Interaction } \\
\hline & $\begin{array}{l}\text { Pre }(N=51) \\
M(S D)\end{array}$ & $\begin{array}{l}\text { Post }(\mathrm{N}=48) \\
\mathrm{M}(\mathrm{SD})\end{array}$ & $\begin{array}{l}\text { Pre }(N=55) \\
M(S D)\end{array}$ & $\begin{array}{l}\text { Post }(N=43) \\
M(S D)\end{array}$ & $F$ & $p$ & $F$ & $p$ & $F$ & $p$ & $\eta 2$ \\
\hline \multicolumn{12}{|l|}{ Anthropometric variables } \\
\hline BMI & $30.15(2.96)$ & $30.48(3.04)$ & $30.08(2.65)$ & $29.64(2.62)$ & .514 & .47 & .702 & .40 & 23.1 & .00 & .183 \\
\hline Waist circumference $(\mathrm{cm})$ & $98.1(7.9)$ & $97.6(7.7)$ & $99.9(9.3)$ & $98.2(9.2)$ & 18.10 & .00 & .549 & .46 & 5.28 & .02 & .050 \\
\hline Hip perimeter $(\mathrm{cm})$ & $106.2(6.8)$ & $105.4(6.8)$ & $106.2(5.2)$ & $105.1(5.3)$ & 30.72 & .00 & .026 & .87 & .585 & .44 & .006 \\
\hline \multicolumn{12}{|c|}{ Psychological and lifestyle variables } \\
\hline PA & $5148.8(5143.3)$ & $3836.3(3680)$ & $6230.2(8683.6)$ & 6975.2(9714.7) & .180 & .67 & 2.17 & .14 & 2.36 & .12 & .025 \\
\hline Quality of life & $7.1(1.1)$ & $7.13(1.3)$ & $7.01(1.3)$ & $7.15(1.24)$ & .258 & .61 & .084 & .77 & .815 & .36 & .009 \\
\hline Self-efficacy & $33.1(4.2)$ & $32.1(5.2)$ & $31.6(5.4)$ & $32.1(4.4)$ & .311 & .57 & .707 & .40 & 3.40 & .06 & .035 \\
\hline \multicolumn{12}{|l|}{ Motivation towards food } \\
\hline Intrinsic & $13.1(2.8)$ & $13.5(2.9)$ & $13.1(3.41)$ & $13.3(3.4)$ & 1.69 & .19 & .008 & .93 & .162 & .68 & .002 \\
\hline Identified & $13.0(2.0)$ & $13.1(1.8)$ & $13.1(1.7)$ & $13.1(1.8)$ & .232 & .63 & .003 & .95 & .025 & .87 & .000 \\
\hline Introjected & $9.2(3.1)$ & $8.8(3.2)$ & $9.8(2.5)$ & $9.6(2.6)$ & 1.501 & .22 & 1.27 & .26 & .170 & .68 & .002 \\
\hline External & $8.4(3.7)$ & $8.1(3.4)$ & $8.6(3.5)$ & $8.3(3.4)$ & 1.04 & .31 & .101 & .75 & .002 & .96 & .000 \\
\hline Demotivation & $6.8(2.8)$ & $6.6(2.7)$ & $7.3(3.1)$ & $7.4(3.3)$ & .001 & .97 & 1.28 & .26 & .211 & .64 & .002 \\
\hline \multicolumn{12}{|l|}{ Motivation towards PA } \\
\hline Intrinsic & $15.4(3.4)$ & $14.9(3.3)$ & $14.9(3.8)$ & $15.0(3.7)$ & 1.51 & .22 & .074 & .78 & 5.74 & .01 & .059 \\
\hline Identified & $15.4(2.6)$ & $15.0(2.6)$ & $15.3(3.4)$ & $15.7(2.9)$ & .007 & .93 & .192 & .66 & 2.85 & .09 & .030 \\
\hline Introjected & $8.4(3.3)$ & $8.83(3.6)$ & $9.39(3.2)$ & $9.45(3.2)$ & .912 & .34 & 1.33 & .25 & .482 & .48 & .005 \\
\hline External & $6.88(3.6)$ & $6.83(3.3)$ & $7.54(4.0)$ & $7.52(3.7)$ & .010 & .92 & .934 & .33 & .002 & .96 & .000 \\
\hline Demotivation & $6.16(3.0)$ & $6.13(2.7)$ & $5.66(2.1)$ & $5.60(2.1)$ & .042 & .83 & 1.15 & .28 & .009 & .92 & .000 \\
\hline \multicolumn{12}{|l|}{ Eating style (DEBQ) } \\
\hline Emotional & $29.06(11.1)$ & 29.74(11.9) & $27.27(10.6)$ & $26.37(9.3)$ & .039 & .84 & 1.49 & .22 & 1.80 & .18 & .019 \\
\hline External & $29.23(7.6)$ & $29.58(7.4)$ & $28.53(6.5)$ & $27.16(5.8)$ & 1.61 & .20 & 1.35 & .24 & 4.58 & .03 & .046 \\
\hline Restrictive & $28.44(6.5)$ & $29.23(6.4)$ & $28.00(5.5)$ & $29.81(5.7)$ & 3.80 & .05 & .242 & .62 & .001 & .97 & .000 \\
\hline \multicolumn{12}{|l|}{ Mood state (DASS) } \\
\hline Depression & $2.61(3.1)$ & $2.79(3.5)$ & $3.80(4.6)$ & $2.88(3.6)$ & .923 & .33 & .861 & .35 & 2.08 & .15 & .021 \\
\hline Anxiety & $1.97(2.7)$ & $3.04(3.4)$ & $2.92(3.5)$ & $1.73(2.6)$ & .055 & .81 & .099 & .75 & 18.5 & .00 & .167 \\
\hline Stress & $4.34(3.6)$ & $5.20(4.1)$ & $5.44(3.8)$ & $3.40(2.9)$ & 3.08 & .08 & .276 & .60 & 18.6 & .00 & .167 \\
\hline
\end{tabular}

Mean and standard deviation of pre- and post- moments and $2 \times 2$ ANOVAs results.

the CG, significant changes were found for the hip perimeter compared to the baseline and compared to moment 2 (M2: before the intervention). Values for waist circumference also decreased compared to the baseline (Table 7 and Fig. 7).

\section{Discussion}

This study shows that" Living Better" results in significant weight loss and reductions in waist circumference compared to the CG. These

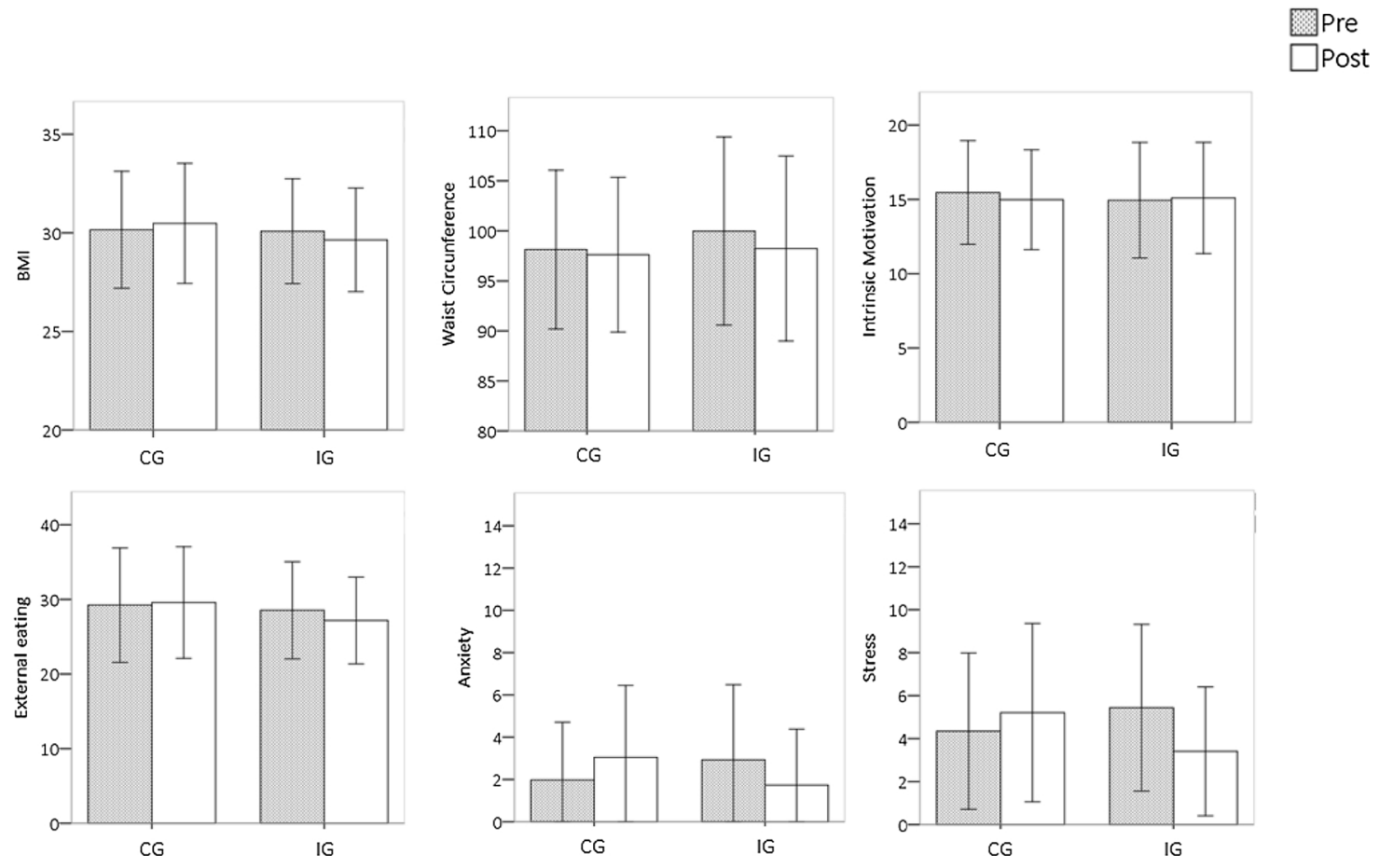

Fig. 2. Pre- and post- differences between the IG and the CG. 
Table 3

XXX.

\begin{tabular}{|c|c|c|c|c|c|c|c|c|c|}
\hline \multirow[t]{2}{*}{ Variables } & \multirow{2}{*}{$\begin{array}{l}\text { Pre(M1) } \\
(\mathrm{N}=55) \\
\mathrm{M}(\mathrm{SD})\end{array}$} & \multirow{2}{*}{$\begin{array}{l}\text { Post(M2) } \\
(\mathrm{N}=43) \\
\mathrm{M}(\mathrm{SD})\end{array}$} & \multirow{2}{*}{$\begin{array}{l}\text { Follow-up (post-intervention, M3) } \\
(\mathrm{N}=20) \\
\mathrm{M}(\mathrm{SD})\end{array}$} & \multicolumn{3}{|c|}{ Moment Effect } & \multicolumn{3}{|c|}{ Contrasts (p) } \\
\hline & & & & $\mathrm{F}$ & $\mathrm{p}$ & $\eta 2$ & Mom 1-2 & Mom 2-3 & Mom 1-3 \\
\hline$P A$ & $5886.9(7434.3)$ & $8595.9(13,282.4)$ & $9428.5(14,210.1)$ & 2.98 & .08 & .13 & .12 & .29 & .07 \\
\hline Quality of life & $7.08(1.3)$ & $7.40(1.1)$ & $6.93(1.1)$ & 1.28 & .29 & .06 & .32 & .11 & .62 \\
\hline Self-efficacy & 29.95(6.6) & $31.85(3.6)$ & $31.75(4.8)$ & 1.14 & .31 & .05 & .17 & .92 & .32 \\
\hline \multicolumn{10}{|c|}{ Motivation towards food } \\
\hline Intrinsic & $13.57(2.5)$ & $13.89(2.5)$ & $13.37(3.1)$ & .471 & .62 & .02 & .54 & .34 & .72 \\
\hline Identified & $13.21(1.6)$ & $13.52(1.4)$ & $13.36(1.5)$ & .368 & .69 & .02 & .34 & .66 & .70 \\
\hline Introjected & $9.74(2.3)$ & $9.58(2.4)$ & $9.84(1.8)$ & .121 & .88 & .00 & .81 & .57 & .82 \\
\hline External & $9.26(3.9)$ & $8.31(3.7)$ & $7.78(3.1)$ & 2.81 & .07 & .13 & .14 & .35 & .05 \\
\hline Demotivation & $6.00(2.3)$ & $5.78(2.4)$ & $6.26(2.4)$ & .298 & .74 & .01 & .73 & .45 & .67 \\
\hline \multicolumn{10}{|c|}{ Motivation towards PA } \\
\hline Intrinsic & $14.52(3.3)$ & $14.73(3.0)$ & $14.26(3.7)$ & .410 & .59 & .02 & .50 & .42 & .67 \\
\hline Identified & $15.26(2.5)$ & $15.47(2.4)$ & $15.10(3.3)$ & .256 & .77 & .01 & .69 & .50 & .74 \\
\hline Introjected & $9.68(3.3)$ & $9.63(3.0)$ & $9.21(3.3)$ & .426 & .65 & .02 & .91 & .46 & .46 \\
\hline External & $8.73(3.9)$ & $7.68(3.4)$ & $7.57(4.2)$ & 1.20 & .30 & .06 & .25 & .84 & .24 \\
\hline Demotivation & $6.10(2.4)$ & $5.78(2.3)$ & $5.63(2.0)$ & .479 & .62 & .02 & .54 & .76 & .29 \\
\hline \multicolumn{10}{|c|}{ Eating style (DEBQ) } \\
\hline Emotional & $27.31(10.0)$ & $25.10(8.6)$ & $26.47(10.8)$ & 1.32 & .28 & .06 & .11 & .39 & .48 \\
\hline External & $28.73(6.6)$ & $26.73(6.4)$ & $26.95(7.6)$ & 4.57 & .01 & .20 & .00 & .80 & .03 \\
\hline Restrictive & $29.84(5.1)$ & $31.57(4.3)$ & $30.57(3.9)$ & 1.79 & .18 & .09 & .08 & .19 & .48 \\
\hline \multicolumn{10}{|c|}{ Mood state (DASS) } \\
\hline Depression & $2.78(4.2)$ & $2.42(2.5)$ & $2.68(2.9)$ & .079 & .92 & .00 & .72 & .72 & .92 \\
\hline Anxiety & $2.94(2.8)$ & $1.16(1.9)$ & $2.16(2.6)$ & 6.80 & .00 & .28 & .00 & .02 & .17 \\
\hline Stress & $5.88(3.7)$ & $3.11(2.3)$ & $4.39(4.0)$ & 6.63 & .00 & .28 & .00 & .08 & .11 \\
\hline
\end{tabular}

Results of 6-month follow-up for the IG: psychological variables.

External eating

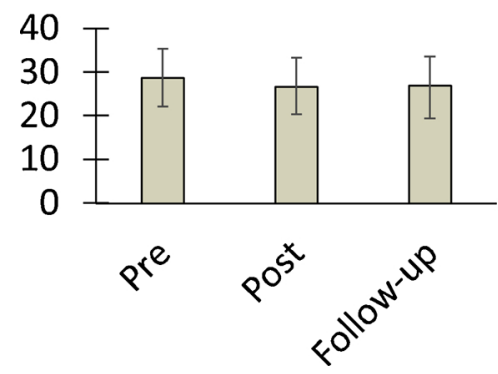

Anxiety

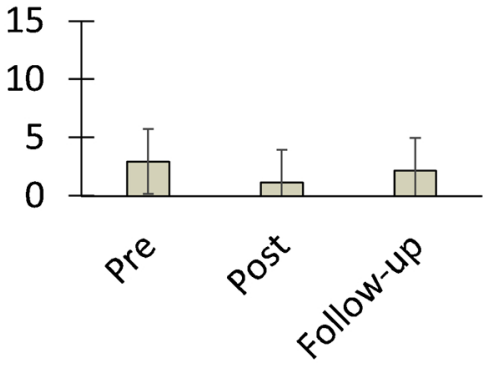

Fig. 3. Six month follow-up results on psychological variables in the IG.

results are in line with other studies in which online programs have been used to improve the general clinical condition of obese and hypertensive patients [44-47]. Our study also shows that these changes in anthropometrical variables are maintained at 12 months follow-up. This fact is of great importance, as the literature points out the difficulties in maintaining changes over time $[48,49]$. It seems that a completely self-administered online program is capable of achieving long-term changes.

"Living Better" has also shown to be efficacious in modifying external eating style. One of the goals of this program is to change eating behaviors (generating a more conscious and less impulsive eating style) using psychoeducation, feeding tricks, and self-control strategies. This finding is relevant as eating styles are considered dimensional and stable and related to obesity [50]. To our knowledge, this is the first study showing the effects of a self-administered online program in changing eating styles.

Regarding mood, anxiety, and stress, scores improved after the intervention, but these changes were not maintained at follow-up. First, it should be noted that the initial scores were low for all groups. It could be hypothesized that modules of cognitive discussion (especially with teaching strategies to deal with problems), problem solving, the influence of thoughts on emotions, and behaviors and emotional regulation strategies may have had a transitory effect on maladaptive moods.

Otherwise, the program was not effective in increasing physical activity. Surprisingly, it is noteworthy that the sample showed high levels of physical activity at baseline, which could have contributed to the absence of significant results. In general, most studies evaluating online interventions for the obese (and hypertensive) population do not take into account the initial levels of physical activity, and (when considered) the results are inconclusive. It is usually concluded that this variable is not easy to change [22].

Data related to the CG are also very positive about the efficacy of "Living Better". The same changes in the IG are also observed in the CG when the intervention was applied, which confirms more emphatically the efficacy of this intervention. In the case of eating styles, the data not only confirmed the external eating reductions but also extended to emotional eating. This result is important as emotional eating is also related to an increase in weight gain over time [51].

In the CG, data also pointed out significant improvements for IPAQshort and QLI. Moreover, unlike the IG group, there was also an increase in the intrinsic and identified motivation and a reduction of external motivation and demotivation to healthy eating. However, the lack of follow-up in this group did not allow confirming if the changes remained in time.

These follow-up data are especially important given that weight management programs often have difficulties in maintaining outcomes $[48,49]$. In addition, few RCTs analyzing online interventions have evaluated the long-term effects of weight loss programs [45], especially 
Table 4

XXX.

\begin{tabular}{|c|c|c|c|c|c|}
\hline \multirow[t]{2}{*}{ Variables } & \multicolumn{2}{|l|}{ Follow-up Moments } & \multicolumn{2}{|c|}{ Effect } & \multirow[b]{2}{*}{$\eta 2$} \\
\hline & $\begin{array}{l}6 \mathrm{~m} .(\mathrm{N}=20) \\
\mathrm{M}(\mathrm{SD})\end{array}$ & $\begin{array}{l}12 \mathrm{~m} .(\mathrm{N}=10) \\
\mathrm{M}(\mathrm{SD})\end{array}$ & $\mathrm{F}$ & $p$ & \\
\hline$P A$ & $4527.9(4232.4)$ & $3673.6(4182.3)$ & 1.53 & .24 & .14 \\
\hline Quality of life & $7.18(1.3)$ & $6.96(1.0)$ & .289 & .60 & .03 \\
\hline Self-efficacy & $32.90(4.3)$ & $33.30(3.0)$ & .116 & .74 & .01 \\
\hline \multicolumn{6}{|c|}{ Motivation towards food } \\
\hline Intrinsic & $13.8(3.3)$ & $13.3(4.0)$ & .918 & .36 & .09 \\
\hline Identified & $14.2(1.2)$ & $13.5(1.8)$ & 1.69 & .22 & .15 \\
\hline Introjected & $10.3(1.6)$ & $10.0(2.2)$ & .403 & .54 & .04 \\
\hline External & $6.60(2.0)$ & $7.80(3.2)$ & 2.25 & .16 & .20 \\
\hline Demotivation & $6.60(2.9)$ & $5.90(3.5)$ & .710 & .42 & .07 \\
\hline \multicolumn{6}{|c|}{ Motivation towards PA } \\
\hline Intrinsic & $13.6(4.4)$ & $13.8(5.0)$ & .055 & .82 & .00 \\
\hline Identified & $155.3(3.5)$ & $15.00(3.8)$ & .336 & .57 & .03 \\
\hline Introjected & $8.70(3.4)$ & $9.60(3.9)$ & 4.31 & .06 & .32 \\
\hline External & $7.10(3.8)$ & $6.50(2.8)$ & .555 & .47 & .05 \\
\hline Demotivation & $5.90(2.5)$ & $6.10(2.9)$ & .231 & .64 & .02 \\
\hline \multicolumn{6}{|c|}{ Eating style (DEBQ) } \\
\hline Emotional & $27.2(11.6)$ & 26.6(11.9) & .133 & .72 & .01 \\
\hline External & $27.7(8.3)$ & $24.8(6.9)$ & 4.00 & .07 & .30 \\
\hline Restrictive & $30.4(4.6)$ & $30.2(5.5)$ & .032 & .86 & .00 \\
\hline \multicolumn{6}{|c|}{ Mood state (DASS) } \\
\hline Depression & $2.90(3.3)$ & $2.50(2.8)$ & .171 & .68 & .01 \\
\hline Anxiety & $1.70(2.3)$ & $2.00(2.4)$ & 1.00 & .34 & .10 \\
\hline Stress & $3.80(3.9)$ & $4.50(3.4)$ & .275 & .61 & .03 \\
\hline
\end{tabular}

Results of the annual follow-up for the IG: psychological variables.

for psychological variables, and when follow-ups have been included, the results are heterogeneous [52-54]. The present study adds evidence on the long-term efficacy of self-administered Internet-based interventions not only for anthropometrical measurements but also for other relevant variables, which could be key for the maintenance of the intervention achievements.

This study has several limitations. Although the follow-up period is 12 months, longer follow-ups are necessary. The dropout rate was high, both in the first phase ( $41 \%$ on average, considering the abandonment of the intervention) and at 12 months follow-up. This finding is relatively common in online interventions but still needs to be discussed, as it could be one of the main barriers to their implementation $[55,56]$. We want to emphasize two characteristics of our study. First, the intervention was completely self-administered. Blended interventions offering some contact with the clinicians could produce better adherence. Second, participants were recruited from a public hospital, and sociodemographic status has been related to treatment adherence for chronic conditions $[57,58]$.

Despite the positive findings, the Internet interventions need to keep improving. First, it could be very useful to include modules related to education and control of cardiovascular health, with special emphasis on blood pressure control and self-care. Second, it may also be useful to complement these interventions with mobile applications, as these tools facilitate better monitoring and self-monitoring in natural contexts

Waist circumference

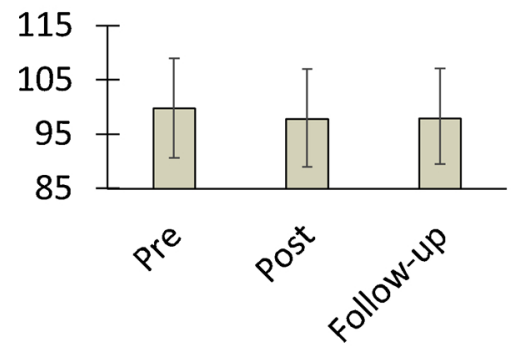

[59], and they have good results when added to the Internet interventions [60-63]. And finally, it is needed to identify the key elements to improve adherence rates and personalize interventions in order to increase effectiveness and reach more people in need.

In conclusion, this study provides evidence that a self-administered online program can be used to provide improvements in relevant variables in the short and long term, and can be useful in the prevention and treatment of obesity and hypertension [64,65]. Internet-based programs are considered cost-effective, as their flexibility makes it possible to deliver interventions to a large number of people. This costeffectiveness could be even higher when the intervention is completely self-administered. However, more studies analyzing the feasibility and effectiveness of Internet interventions are still needed in order to implement more cost-effective interventions.

\section{Author contributions}

- Conceived and designed the trial: MM, AC, ER, JFL.

- Designed the Online Intervention: MM, AC, CB, RMB.

- Performed the trial: MM, GP, FFA, SJM.

- Analyzed the data: MM, AC, ER, GP, JFL, CB, RMB.

- Contributed reagents/materials/analysis tools: CB, FFA, SJM.

- Wrote the paper: MM, AC, ER, GP, JFL, CB, FFA, SJM, RMB.

\section{Statement on conflicts of interest}

The authors have declared that no competing interests exist.

\section{Summary table}

- Lifestyles are one of the most important determinants of health, and they have a decisive influence on the maintenance of chronic diseases, including obesity and arterial hypertension.

- The efficacy of ICTs for delivering treatments for several chronic diseases has already been proven, including Internet-based interventions to promote weight loss or improve lifestyle.

- There are no studies that evaluate the efficacy of a self-administered online intervention on anthropometric and psychological variables jointly in a sample of obese patients with hypertension.

- This study provides evidence that a self-administered online program can be used to provide improvements in relevant variables in the short and long term (12 months follow-up).

- These data support the utility of self-administered online programs in the prevention and treatment of obesity and hypertension.

- Internet-based programs are considered cost-effective. This cost-effectiveness could be even higher when the intervention is completely self-administered.

\section{Funding sources}

This research was partially supported by CIBER-Obn. The funder had no role in study design, data collection and analysis, decision to

Fig. 4. Annual follow-up results on anthropometric variables in the IG.

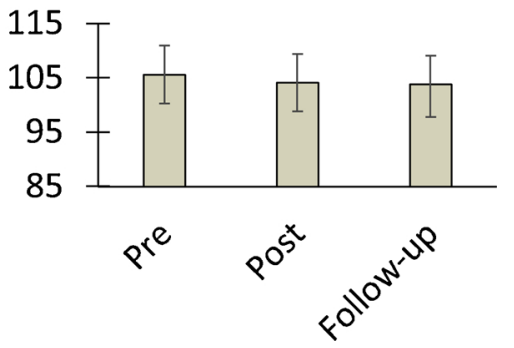


Table 5

XXX.

\begin{tabular}{|c|c|c|c|c|c|c|c|c|c|}
\hline \multirow[t]{2}{*}{ Variables } & \multirow{2}{*}{$\begin{array}{l}\text { Pre(M1) } \\
(\mathrm{N}=55)\end{array}$} & \multirow{2}{*}{$\begin{array}{l}\text { Post(M2) } \\
(\mathrm{N}=43)\end{array}$} & \multirow{2}{*}{$\begin{array}{l}12 \text { m.fw-up (M4) } \\
(\mathrm{N}=10) \\
\mathrm{M}(\mathrm{SD})\end{array}$} & \multicolumn{3}{|c|}{ Moment Effect } & \multicolumn{3}{|c|}{ Contrasts (p) } \\
\hline & & & & $\mathrm{F}$ & $\mathrm{p}$ & $\eta 2$ & Mom 1-2 & Mom 2-4 & Mom 1-4 \\
\hline BMI & $30.0(2.68)$ & $29.52(2.52)$ & $29.8(2.46)$ & 3.19 & .06 & .07 & .00 & .32 & .20 \\
\hline Waist circumference $(\mathrm{cm})$ & $99.8(9.2)$ & $97.8(8.9)$ & $97.93(8.5)$ & 9.89 & .00 & .20 & .00 & .81 & .00 \\
\hline Hip perimeter $(\mathrm{cm})$ & $105.6(5.3)$ & $104.1(5.3)$ & $103.8(6.0)$ & 11.68 & .00 & .23 & .00 & .53 & .00 \\
\hline
\end{tabular}

Results of the annual follow-up for the IG: anthropometric variables.

Table 6

XXX.

\begin{tabular}{|c|c|c|c|c|c|c|c|c|c|}
\hline \multirow[t]{2}{*}{ Variables } & \multirow{2}{*}{$\begin{array}{l}\text { Pre-waiting list (base line-M1) } \\
(\mathrm{N}=51) \\
\mathrm{M}(\mathrm{SD})\end{array}$} & \multirow{2}{*}{$\begin{array}{l}\text { Post-waiting list (Pre- intervention-M2) } \\
(\mathrm{N}=48) \\
\mathrm{M}(\mathrm{SD})\end{array}$} & \multirow{2}{*}{$\begin{array}{l}\text { Post-intervention(M3) } \\
(\mathrm{N}=19) \\
\mathrm{M}(\mathrm{SD})\end{array}$} & \multicolumn{3}{|l|}{ Effects } & \multicolumn{3}{|c|}{ Contrasts $(p)$} \\
\hline & & & & $\mathrm{F}$ & $p$ & $\eta 2$ & Mom1-2 & Mom 2-3 & Mom 1-3 \\
\hline$P A$ & $6705.7(5658)$ & $4611.4(3619)$ & $6808.41(5772)$ & 2.40 & .10 & .13 & .09 & .05 & .93 \\
\hline Quality of life & $7.45(0.7)$ & $7.41(1.2)$ & $7.76(1.0)$ & 2.21 & .12 & .12 & .89 & .04 & .06 \\
\hline Self-efficacy & $33.37(3.9)$ & $34.00(4.0)$ & $34.25(4.2)$ & .753 & .48 & .04 & .43 & .74 & .20 \\
\hline \multicolumn{10}{|c|}{ Motivation towards food } \\
\hline Intrinsic & $13.37(3.3)$ & $14.18(2.8)$ & $15.00(2.5)$ & 3.46 & .04 & .18 & .16 & .25 & .01 \\
\hline Identified & $12.93(2.5)$ & $14.12(1.3)$ & $14.25(1.0)$ & 3.98 & .04 & .21 & .05 & .66 & .04 \\
\hline Introjected & $9.81(3.0)$ & $9.87(3.4)$ & $10.18(2.6)$ & .198 & .82 & .01 & .93 & .57 & .58 \\
\hline External & $8.93(4.4)$ & $7.37(3.1)$ & $6.12(4.4)$ & 5.77 & .00 & .27 & .06 & .25 & .00 \\
\hline Demotivation & $6.81(1.8)$ & $5.43(1.8)$ & $5.00(2.1)$ & 2.91 & .07 & .16 & .08 & .55 & .05 \\
\hline \multicolumn{10}{|c|}{ Motivation towards PA } \\
\hline Intrinsic & $16.43(3.2)$ & $15.81(3.0)$ & $16.68(3.7)$ & 1.73 & .19 & .10 & .13 & .06 & .67 \\
\hline Identified & $16.37(2.3)$ & $16.25(1.9)$ & $16.68(2.0)$ & .235 & .79 & .01 & .85 & .54 & .61 \\
\hline Introjected & $9.81(3.6)$ & $9.56(3.6)$ & $9.43(3.5)$ & .175 & .84 & .01 & .60 & .86 & .59 \\
\hline External & $7.06(4.3)$ & $5.93(3.1)$ & $6.12(4.4)$ & 1.49 & .24 & .09 & .16 & .79 & .14 \\
\hline Demotivation & $5.62(2.9)$ & $4.93(1.9)$ & $4.31(0.8)$ & 2.03 & .14 & .12 & .32 & .27 & .08 \\
\hline \multicolumn{10}{|c|}{ Eating style (DEBQ) } \\
\hline Emotional & $26.18(9.2)$ & $26.12(9.1)$ & $23.43(9.7)$ & 3.80 & .03 & .20 & .95 & .03 & .03 \\
\hline External & $28.62(9.1)$ & $28.12(7.0)$ & $25.68(7.5)$ & 3.46 & .04 & .18 & .67 & .04 & .03 \\
\hline Restrictive & $28.1(6.3)$ & $29.18(6.1)$ & $29.25(4.3)$ & .521 & .59 & .03 & .38 & .95 & .44 \\
\hline \multicolumn{10}{|c|}{ Mood state (DASS) } \\
\hline Depression & $1.87(2.2)$ & $2.75(2.6)$ & $1.68(1.9)$ & 1.40 & .26 & .08 & .25 & .16 & .74 \\
\hline Anxiety & $1.33(1.8)$ & $2.40(1.6)$ & $1.26(2.0)$ & 3.19 & .05 & .18 & .07 & .01 & .90 \\
\hline Stress & $3.60(3.4)$ & $4.80(3.3)$ & $2.53(2.3)$ & 3.15 & .05 & .18 & .15 & .03 & .28 \\
\hline
\end{tabular}

Results of 6-month follow-up for the CG: psychological variables.

Intrinsic motivation

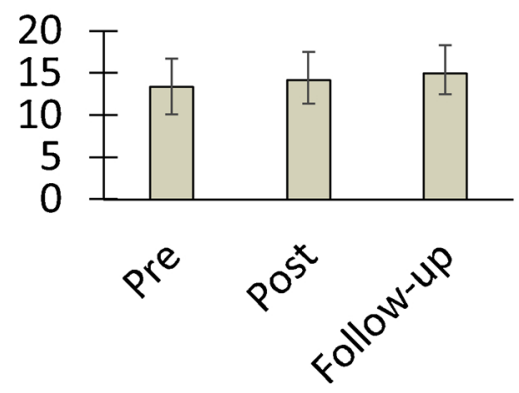

External motivation

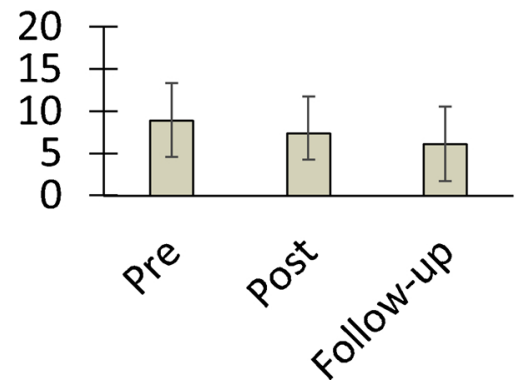

Identified motivation

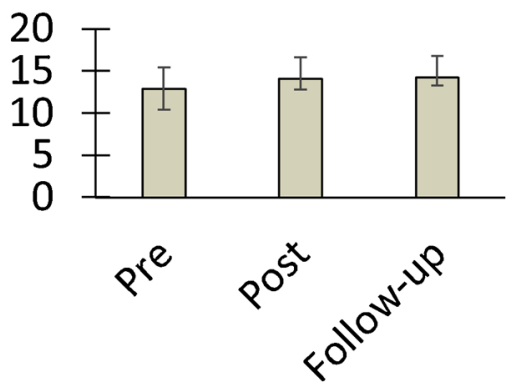

Demotivation

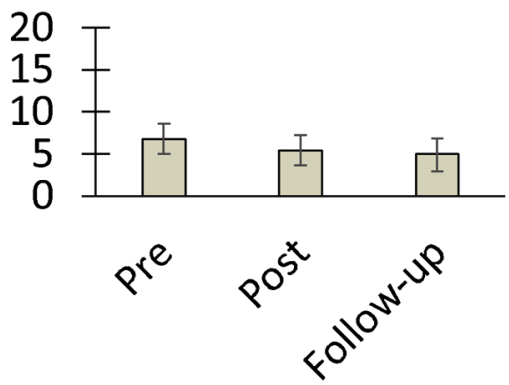

Fig. 5. Follow-up results on motivational variables in the CG. 
Emotional eating

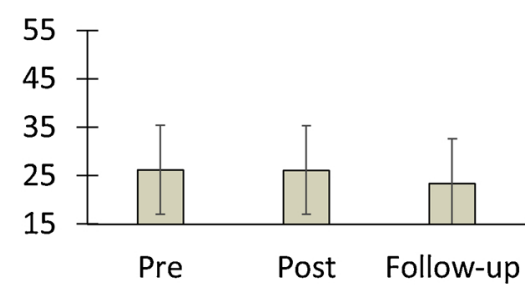

Anxiety

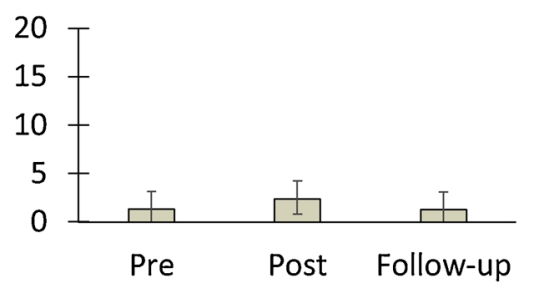

Physical activity

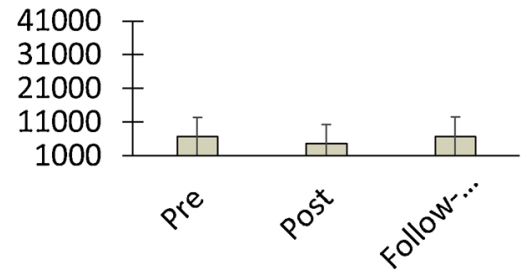

External eating

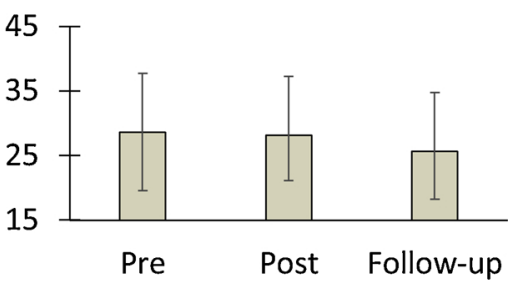

Stress

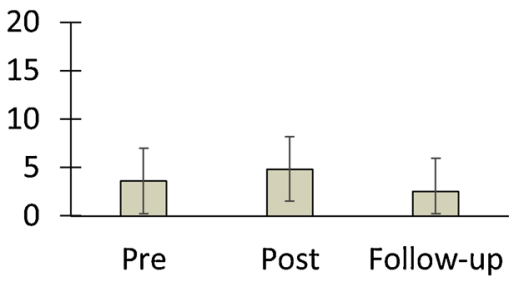

Quality of life

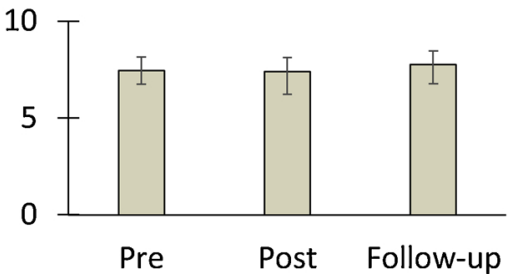

Fig. 6. Follow-up results on psychological variables in the CG.

Table 7

XXX.

\begin{tabular}{|c|c|c|c|c|c|c|c|c|c|}
\hline \multirow[t]{2}{*}{ Variables } & \multirow{2}{*}{$\begin{array}{l}\text { Pre/base line (M1) } \\
(\mathrm{N}=51) \\
\mathrm{M}(\mathrm{SD})\end{array}$} & \multirow{2}{*}{$\begin{array}{l}\text { Pre-intervention (M2) }(\mathrm{N}=48) \\
\mathrm{M}(\mathrm{SD})\end{array}$} & \multirow{2}{*}{$\begin{array}{l}6 \mathrm{~m} \mathrm{fw}-\text { up }(\mathrm{M} 4)(\mathrm{N}=33) \\
\mathrm{M}(\mathrm{SD})\end{array}$} & \multicolumn{3}{|c|}{ Moment Effect } & \multicolumn{3}{|c|}{ Contrasts (p) } \\
\hline & & & & $\mathrm{F}$ & $\mathrm{p}$ & $\eta 2$ & Mom1-2 & Mom2-4 & Mom 1-4 \\
\hline BMI & $30.34(3.1)$ & $29.7(6.1)$ & $29.8(3.5)$ & .336 & .59 & .01 & .53 & .96 & .08 \\
\hline Waist circumference $(\mathrm{cm})$ & $99.2(6.6)$ & $98.85(6.3)$ & $97.12(8.2)$ & 3.36 & .05 & .10 & .45 & .09 & .03 \\
\hline Hip perimeter $(\mathrm{cm})$ & 106.5(7.1) & $105.8(6.7)$ & $104.3(7.2)$ & 8.78 & .00 & .22 & .03 & .02 & .00 \\
\hline
\end{tabular}

Results of the annual follow-up for the CG: anthropometric variables.

Hip perimeter

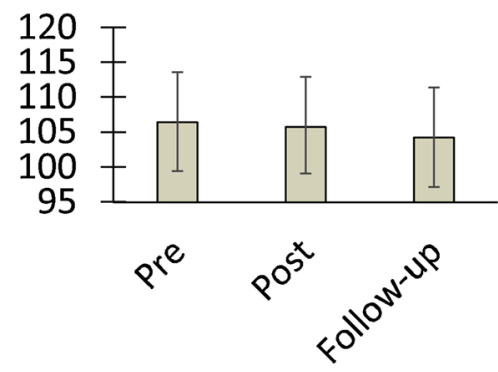

Waist circumference

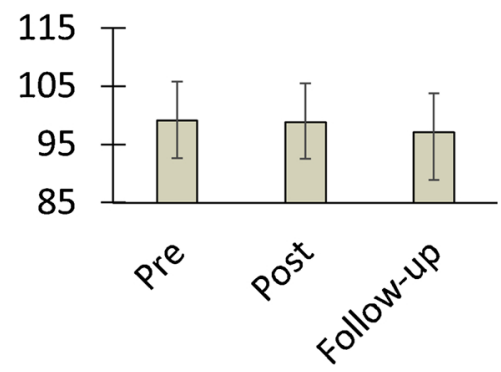

Fig. 7. Annual follow-up results on anthropometric variables in the CG.

publish, or preparation of the manuscript.

\section{Acknowledgements}

CBER Fisiopatología de la Obesidad y Nutrición (CIBERobn) is an initiative of ISCIII.MM is grateful to CAPES/Brazil (Coordination for the Improvement of Higher Level Personnel) for the doctoral scholarship.

\section{References}

[1] R. Lowry, H. Wechsler, D.A. Galuska, J.E. Fulton, L. Kann, Television viewing and its associations with overweight, sedentary lifestyle, and insufficient consumption of fruits and vegetables among US high school students: differences by race, ethnicity, and gender, J. Sch. Health 72 (2002) 413-421.

[2] C. Ng, T.K. Young, P.N. Corey, Associations of television viewing, physical activity and dietary behaviours with obesity in aboriginal and non-aboriginal Canadian youth, Public Health Nutr 13 (2010) 1430-1437, https://doi.org/10.1017/ S1368980010000832.

[3] A.M. Prentice, The emerging epidemic of obesity in developing countries, Int. J. 
Epidemiol. 35 (2006) 93-99, https://doi.org/10.1093/ije/dyi272.

[4] A. Marti, M.J. Moreno-Aliaga, J. Hebebrand, et al., Genes, lifestyles and obesity, Int. J. Obes. 28 (Suppl 3) (2004) S29-S36, https://doi.org/10.1038/sj.ijo.0802808.

[5] C.M. Bruno, M.D. Amaradio, G. Pricoco, E. Marino, F. Bruno, Lifestyle and hypertension: an evidence-based review, J. Hypertens. Manag. 4 (1) (2018) 030, https://doi.org/10.23937/2474-3690/1510030.

[6] T. Lehnert, D. Sonntage, A. Konnopka, et al., Economic costs of overweight and obesity, Best Pract. Res. Cl En 27 (2013) 105-115.

[7] W.J. Elliott, The economic impact of hypertension, J. Clin. Hypertens. 5 (2003) 3-13, https://doi.org/10.1111/j.1524-6175.2003.02463.x.

[8] C. Foster, M. Hillsdon, M. Thorogood, Interventions for promoting physical activity, Cochrane Database Syst. Rev. 1 (2005), https://doi.org/10.1002/14651858. CD003180.pub2 CD003180.

[9] M. Mauro, V. Taylor, S. Wharton, A.M. Sharma, Barriers to obesity treatment, Eur. J. Intern. Med. 19 (2008) 173-180, https://doi.org/10.1016/j.ejim.2007.09.011.

[10] D. Siegel, Barriers to and strategies for effective blood pressure control, Vasc. Health Risk Manag. 1 (1) (2005) 9-14.

[11] R.A. Krukowski, D.S. West, J. Harvey-Berino, Recent advances in internet-delivered, evidence-based weight control programs for adults, J. Diabetes Sci. Technol. 3 (2009) 184-189.

[12] C.L. Paul, M.L. Carey, R.W. Sanson-Fisher, L.E. Houlcroft, H.E. Turon, The impact of web-based approaches on psychosocial health in chronic physical and mental health conditions, Health Educ. Res. 28 (3) (2013) 450-471, https://doi.org/10.1093/ her/cyt053.

[13] L. Kooij, W.G. Groen, W.H. van Harten, The effectiveness of information technology-supported shared care for patients with chronic disease: a systematic review, J. Med. Internet Res. 19 (6) (2017) e221.

[14] M. Neve, P.J. Morgan, P.R. Jones, C.E. Collins, Effectiveness of web-based interventions in achieving weight loss and weight loss maintenance in overweight and obese adults: a systematic review with meta-analysis, Obes. Rev. 11 (2010) 306-321, https://doi.org/10.1111/j.1467-789X.2009.00646.x.

[15] G.M. Manzoni, F. Pagnini, S. Corti, E. Molinari, G. Castelnuovo, Internet-based behavioral interventions for obesity: an updated systematic review, Clin. Pract. Epidemiol. Ment. Health 7 (2011) 19-28, https://doi.org/10.2174/ 1745017901107010019.

[16] S. Kodama, K. Saito, S. Tanaka, C. Horikawa, K. Fujiwara, R. Hirasawa, H. Sone, Effect of web-based lifestyle modification on weight control: a meta-analysis, Int. J. Obes. 36 (2012) 675-685, https://doi.org/10.1038/ijo.2011.121.

[17] G.R. Dutton, M.H. Laitner, M.G. Perri, Lifestyle interventions for cardiovascular disease risk reduction: a systematic review of the effects of diet composition, food provision, and treatment modality on weight loss, Curr. Atheroscler. Rep. 16 (2014) 442, https://doi.org/10.1007/s11883-014-0442-0.

[18] R.P. Nolan, S. Liu, J.K. Shoemaker, V. Hachinski, H. Lynn, D.J. Mikulis, A. Zbib, Therapeutic benefit of internet-based lifestyle counselling for hypertension, Can. J. Cardiol. 28 (2012) 390-396, https://doi.org/10.1016/j.cjca.2012.02.012.

[19] I.L. Vegting, E.J.M. Schrijver, R.H.J. Otten, P.W.B. Nanayakkara, Internet programs targeting multiple lifestyle interventions in primary and secondary care are not superior to usual care alone in improving cardiovascular risk profile: a systematic review, Eur. J. Intern. Med. 25 (2014) 73-81, https://doi.org/10.1016/j.ejim.2013. 08.008 .

[20] S. Weineland, D. Arvidsson, T. Kakoulidis, J. Dahl, Acceptance and commitment therapy for bariatric surgery patients, a pilot RCT, Obes. Res. Clin. Pract. 6 (2012) e1-e90.

[21] P.J. Morgan, D.R. Lubans, C.E. Collins, J.M. Warren, R. Callister, 12-month outcomes and process evaluation of the SHED-IT RCT: an internet-based weight loss program targeting men, Obesity 19 (2011) 142-151, https://doi.org/10.1038/oby. 2010.119.

[22] L.M. Neville, B. O’Hara, A. Milat, Computer-tailored physical activity behavior change interventions targeting adults: a systematic review, Int. J. Behav. Nutr. Phys. Act. 6 (2009) 30.

[23] L. Van Genugten, P. Van Empelen, B. Boon, G. Borsboom, T. Visscher, A. Oenema, Results from an online computer-tailored weight management intervention for overweight adults: randomized controlled trial, J. Med. Internet Res. 14 (2012) e44, https://doi.org/10.2196/jmir.1901.

[24] S. Watson, J. Woodside, L.J. Ware, S.J. Hunter, A. McGrath, C.R. Cardwell, M.C. McKinley, Effect of a web-based behavior change program on weight loss and cardiovascular risk factors in overweight and obese adults at high risk of developing cardiovascular disease: randomized controlled trial, J. Med. Internet Res. 17 (2015) e177, https://doi.org/10.2196/jmir.3828.

[25] J.B. Bennett, K.M. Broome, A. Schwab-Pilley, P. Gilmore, A web-based approach to address cardiovascular risks in managers: results of a randomized trial, J. Occup. Environ. Med. 53 (2011) 911-918, https://doi.org/10.1097/JOM. 0b013e3182258bd8.

[26] A. Zutz, A. Ignaszewski, J. Bates, S.A. Lear, Utilization of the internet to deliver cardiac rehabilitation at a distance: a pilot study, Telemed. J. E Health 13 (2007) 323-330, https://doi.org/10.1089/tmj.2006.0051.

[27] G. Eysenbach, CONSORT-EHEALTH: improving and standardizing evaluation reports of web-based and mobile health interventions, J. Med. Internet Res. 13 (2011) e126.

[28] D. Moher, K.F. Schulz, D.G. Altman, The CONSORT statement: revised recommendations for improving the quality of reports of parallel-group randomized trials, J. Am. Pediatr. Med. Assoc. 91 (2001) 437-442.

[29] R.M. Baños, M.S. Mensorio, A. Cebolla, E. Rodilla, G. Palomar, J.F. Lisón, C. Botella, An internet-based self-administered intervention for promoting healthy habits and weight loss in hypertensive people who are overweight or obese: a randomized controlled trial, BMC Cardiovasc. Disord. 15 (2015) 83, https://doi.org/10.1186/ s12872-015-0078-1.

[30] L.J. Carr, R.T. Bartee, C. Dorozynski, J.F. Broomfield, M.L. Smith, D.T. Smith, Internet-delivered behavior change program increases physical activity and improves cardiometabolic disease risk factors in sedentary adults: results of a randomized controlled trial, Prev. Med. 46 (2008) 431-438, https://doi.org/10.1016/j. ypmed.2007.12.005.

[31] L.G. Womble, T.A. Wadden, B.G. McGuckin, S.L. Sargent, R.A. Rothman, E.S. Krauthamer-Ewing, A randomized controlled trial of a commercial internet weight loss program, Obes. Res. 12 (2004) 1011-1018.

[32] World Health Organization. (2015). Alimentación Sana. Obtained from http:// www.who.int/mediacentre/factsheets/fs394/es/.

[33] World Health Organization. (2016). Obesity and overweight. Obtained from http:// www.who.int/mediacentre/factsheets/fs311/en/index.html.

[34] M.L. Booth, Assessment of physical activity: an international perspective, Res. Exerc. Sport 71 (2000) S114-120.

[35] J.E. Mezzich, N.L. Cohen, M.A. Ruiperez, A quality of life index: brief description and validation, Paper Presented at the International Congress of the International Federation for Psychiatric Epidemiology (1996).

[36] J.E. Mezzich, M.A. Ruipérez, C. Pérez, G. Yoon, J. Liu, S. Mahmud, The Spanish version of the quality of life index: presentation and validation, J. Nerv. Ment. Dis. 188 (2000) 301-305.

[37] J. Baessler, R. Schwarcer, Evaluación de la autoeficacia: adaptación española de la escala de autoeficacia General, Ansiedad y Estrés 2 (1996) 1-8.

[38] T. Van Strien, J.E.R. Frijters, G.P.A. Bergers, P.B. Defares, The Dutch eating behavior questionnaire (DEBQ) for assessment of restrained, emotional, and external eating behavior, Int. J. Eat. Disord. 5 (1986) 295-315.

[39] A. Cebolla, J.R. Barrada, T. van Strien, E. Oliver, R. Baños, Validation of the Dutch eating behavior questionnaire (DEBQ) in a sample of Spanish women, Appetite 73 (2014) 58-64, https://doi.org/10.1016/j.appet.2013.10.014.

[40] P.F. Lovibond, S.H. Lovibond, The structure of negative emotional states: comparison of the depression anxiety stress scales (DASS) with the beck depression and anxiety inventories, Behav. Res. Ther. 33 (1995) 335-343.

[41] A. Bados, A. Solanas, R. Andrés, Psychometric properties of the Spanish version of depression, anxiety and stress scales, Psicothema 17 (2005) 679-683.

[42] D. Markland, V. Tobin, A modification to behavioural regulation in exercise questionnaire to include an assessment of amotivation, J. Sport Exerc. Psychol. 26 (2004) 191-196.

[43] J.A. Moreno, E. Cervelló, A. Martínez, Measuring self-determination motivation in a physical fitness setting; Validation of the behavioural regulation in exercise questionnaire-2 (BREQ-2) in a Spanish sample, J. Sports Med. Phys. Fit. 47 (2006) $366-378$.

[44] J. Harvey-Berino, S. Pintauro, P. Buzzell, E.C. Gold, Effect of internet support on the long-term maintenance of weight loss, Obes. Res. 12 (2004) 320-329.

[45] D.M. Levine, S. Savarimuthu, A. Squires, J. Nicholson, M. Jay, Technology-assisted weight loss interventions in primary care: a systematic review, J. Gen. Intern. Med. 30 (2015) 107-117, https://doi.org/10.1007/s11606-014-2987-6.

[46] P.J. Morgan, D.R. Lubans, C.E. Collins, J.M. Warren, R. Callister, The SHED-IT randomized controlled trial: evaluation of an internet-based weight-loss program for men, Obesity 17 (2009) 2025-2032, https://doi.org/10.1038/oby.2009.85.

[47] L.C.H. Raaijmakers, S. Pouwels, K.A. Berghuis, S.W. Nienhuijs, Technology-based interventions in the treatment of overweight and obesity: a systematic review, Appetite 95 (2015) 138-151, https://doi.org/10.1016/j.appet.2015.07.008.

[48] L. Khaodhiar, G.L. Blackburn, Obesity treatment: factors involved in weight-loss maintenance and regain, Curr. Opin. Endocrinol. Diabetes 9 (2002) 369-374, https://doi.org/10.1097/00060793-200210000-00002.

[49] R. Ross, The challenge of obesity treatment: avoiding weight regain, CMAJ 180 (2009) 997-998, https://doi.org/10.1503/cmaj.090427.

[50] R.M. Baños, A. Cebolla, I. Moragrega, T. Van Strien, F. Fernández-Aranda, Z. Agüera, C. Botella, Relationship between eating styles and temperament in an anorexia nervosa, healthy control, and morbid obesity female sample, Appetite 76 (2014) 76-83, https://doi.org/10.1016/j.appet.2014.01.012.

[51] M. Frayn, B. Knäuper, Emotional eating and weight in adults: a review, Curr. Psychol. (2017) 1-10, https://doi.org/10.1007/s12144-017-9577-9.

[52] C.R.L. Beishuizen, B.C.M. Stephan, W.A. Van Gool, C. Brayne, R.J.G. Peters, S. Andrieu, E. Richard, Web-based interventions targeting cardiovascular risk factors in middle-aged and older people: a systematic review and meta-analysis, J. Med. Internet Res. 18 (2016) e55, https://doi.org/10.2196/jmir.5218.

[53] J. Harvey-Berino, D. West, R. Krukowski, E. Prewitt, A. VanBiervliet, T. Ashikaga, J. Skelly, Internet delivered behavioral obesity treatment, Prev. Med. 51 (2010) 123-128, https://doi.org/10.1016/j.ypmed.2010.04.018.

[54] A. Sherrington, J.J. Newham, R. Bell, A. Adamson, E. Mccoll, V. Araujo-Soares, Systematic review and meta-analysis of internet-delivered interventions providing personalized feedback for weight loss in overweight and obese adults, Obes. Rev. 17 (2016) 541-551, https://doi.org/10.1111/obr.12396.

[55] Á. McConnon, S.F.L. Kirk, J.E. Cockroft, E.L. Harvey, D.C. Greenwood, J.D. Thomas, L. Bojke, The internet for weight control in an obese sample: results of a randomised controlled trial, BMC Health Serv. Res. 7 (2007) 206, https://doi.org/10.1186/ 1472-6963-7-206.

[56] D.J. Wantland, C.J. Portillo, W.L. Holzemer, R. Slaughter, E.M. McGhee, The effectiveness of web-based vs. non-web-based interventions: a meta-analysis of behavioral change outcomes, J. Med. Internet Res. 6 (2004) e40.

[57] M.R. Di Matteo, Variations in patients' adherence to medical recommendations: a quantitative review of 50 years of research, Med. Care 42 (2004) 200-209, https:// doi.org/10.1097/01.mlr.0000114908.90348.f9.

[58] M.E. Falagas, E.A. Zarkadoulia, P.A. Pliatsika, G. Panos, Socioeconomic status (SES) as a determinant of adherence to treatment in HIV infected patients: a systematic 
review of the literature, Retrovirology 5 (2008) 13, https://doi.org/10.1186/17424690-5-13.

[59] J.E. Chua, J.A. Zaldua, T.J. Sevilla, M.J. Tapel, M.R. Orlino, R.D. Camilo, L.C. Manuela, An android phone application for a health monitoring system with integrated medical devices and localized health information and database for healthy lifestyle changes, Paper Presented at 2014 International Conference on Humanoid, Nanotechnology, Information Technology, Communication and Control, Environment and Management (HNICEM) (2014), https://doi.org/10. 1109/HNICEM.2014.7016204.

[60] I. Hallberg, A. Ranerup, K. Kjellgren, Supporting the self-management of hypertension: patients' experiences of using a mobile phone-based system, J. Hum. Hypertens. 30 (2016) 141-146.

[61] C.J. Kim, E.A. Schlenk, S.W. Kang, J.B. Park, Effects of an internet-based lifestyle intervention on cardio-metabolic risks and stress in korean workers with metabolic syndrome: a controlled trial, Patient Educ. Couns. 98 (2015) 111-119, https://doi. org/10.1016/j.pec.2014.10.013.
[62] M. Mehring, M. Haag, K. Linde, S. Wagenpfeil, F. Frensch, J. Blome, A. Schneider, Effects of a general practice guided web-based weight reduction program - results of a cluster-randomized controlled trial, BMC Fam. Pract. 14 (2013) 76, https://doi. org/10.1186/1471-2296-14-76.

[63] M. Park, H. Kim, Evaluation of mobile phone and internet intervention on waist circumference and blood pressure in post-menopausal women with abdominal obesity, Int. J. Med. Inf. 81 (2012) 388-394, https://doi.org/10.1016/j.ijmedinf. 2011.12.011.

[64] B.L. Elder, E.M. Ammar, D. Pile, Sleep duration, activity levels, and measures of obesity in adults, Public. Health Nurs. 33 (2016) 200-205, https://doi.org/10. 1111/phn.12230.

[65] C. Wilborn, J. Beckham, B. Campbell, T. Harvey, M. Galbreath, P. La Bounty, E. Nassar, J. Wismann, R. Kreider, Obesity: prevalence, theories, medical consequences, management, and research directions, J. Int. Soc. Sports Nutr. 2 (2005) 4-31. 